\title{
Influence of Polymerization Degree and Its Distribution on Thermal Behavior of Thermotropic Nematic Model Compounds
}

\author{
Yoshihiro OGAWA and Kanichiro TAKAMIZAWA* \\ Department of Chemistry, Faculty of General Education, \\ Kumamoto University, Kumamoto 860, Japan \\ * Department of Applied Science, Faculty of Engineering, \\ Kyushu University, Fukuoka 812, Japan
}

(Received December 7, 1988)

\begin{abstract}
A study of oligomers with the repeating unit of an ester of 4,4'-dihydroxybiphenyl and sebacic acid was performed to provide information on the relations of the polymerization degree and its distribution with the liquid crystalline properties of backbone-chain type thermotropic polymeric liquid crystals. To eliminate the effect of the end group, $p$-phenylphenol was connected to each end of the oligomers. The oligomers were separated into single components to provide pure materials of the monomer $\mathrm{B} 8 \mathrm{~B}$ and dimer $(\mathrm{B} 8)_{2} \mathrm{~B}$ and trimer $(\mathrm{B} 8)_{3} \mathrm{~B}$. Each mer was studied by DSC and polarizing microscopy. B8B and $(\mathrm{B} 8)_{2} \mathrm{~B}$ did not show a liquid crystalline phase while (B8) $)_{3} \mathrm{~B}$ formed a monotropic nematic phase, indicating that a liquid cyrstalline phase develops as polymerization proceeds. (B8) ${ }_{3} \mathrm{~B}$ has a phase transition entropy ratio, $\Delta S_{\mathrm{IN}} / \Delta S_{\mathrm{KI}}$ of 0.19 , and the degree of order in its nematic phase is suggested to be as high as that of the liquid crystal of the polymer. Mixtures of $(\mathrm{B} 8)_{2} \mathrm{~B}$ and $(\mathrm{B} 8)_{3} \mathrm{~B}$ formed an enantiotropic nematic phase and a nematic-isotropic $(\mathrm{N}+\mathrm{I})$ biphase when observed by optical microscopy, indicating that its distribution is also a key factor, in addition to polymerization degree, in the development of a polymeric liquid crystalline phase.
\end{abstract}

KEY WORDS Separation of Oligomers / Trimer / Monotropic Nematic /

Polymerization Degree / Repeating Unit / Mixtures / Phase Diagrams /

N+I Biphase /

For thermotropic polymeric liquid crystals consisting of alternating mesogen groups and flexible segments, most studies so far have focused on the relations of their structural elements with their liquid crystalline properties. ${ }^{1}$ To understand how a liquid crystalline phase develops as the polymerization degree increases, however, investigations are required to reveal quantitatively the effects of the polymerization degree and its distribution on the stability of polymers in a mesophase. Two major phenomena have been reported as effects of the polymerization degree. ${ }^{2,3}$ In one, monotropic nematic polymers become enantiotropic nematic as the polymerization degree increases. This phenomenon is of interest in that oligomers of larger polymerization degree form liquid crystals. In the other, the entropy per repeating unit of transition from isotropic liquid into nematic liquid crystal increases with the size of the oligomer, until the dependence finally disappears when the material becomes a polymer, indicating that the degree of order in the nematic phase is different between polymeric liquid crystals and low molecular weight liquid crystals. This suggests that the nematic phase of polymeric liquid crystals may not be interpreted in terms of rod-like molecular model generally used for low molecular weight liquid crystals. Blumstein et al. insist that this 
effect of polymerization degree is attributable to the cooperativity between repeating units in the nematic phase. ${ }^{2}$ Actually, the distribution of polymerization degree and end groups also seem to add complicated effects. To reveal the effect of polymerization degree, therefore, studies should be made by using model compounds that are monodisperse and have the same end group(s). In the present study, we used as model compounds such as.

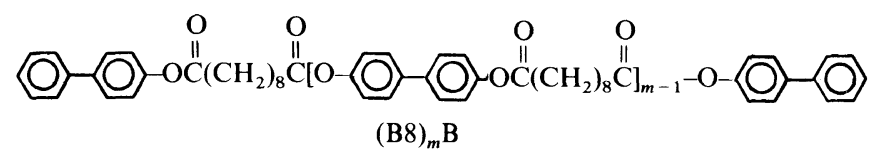

This oligomer consists of an ester (repeating unit) of 4,4'-dihydroxybiphenyl and sebacic acid, and $p$-phenylphenol (end group), which has a similar structure as the mesogen group. The definition of oligomers varies among researchers. For the present study, $m$-mer is defined as $(\mathrm{B} 8)_{m} \mathrm{~B}$, where $\mathrm{B}$ and 8 represent the biphenyl group and the number of methylene segments. We were interested in polymers consisting of such repeating units for the following reason. A detailed study by Krigbaum et al. ${ }^{4}$ suggested that the mesophases of the polymers were smectic $\left(S_{\mathrm{H}}\right)$ when the number of methylene chains was even or nematic when the number was odd. However an optical microscopic observation by van Ruyen et al. ${ }^{5}$ indicated that the mesophases of the polymers were nematic regardless of the number of methylene segments. We thought that the disagreement between the two studies might be attributable to a difference in the polymerization degree and its distribution. In this report, we describe the separation of these oligomers into different mers and discuss the phase transition behavior of the separated mers in terms of thermal measurements.

\section{EXPERIMENTAL}

\section{Monomer}

All reagents, manufactured by Tokyo Kasei Co., were used as supplied. To prepare the monomer $\mathrm{BnB}, p$-phenylphenol and dry toluene-pyridine $(4: 1)$ were added in excess to sebacoyl chloride and subjected to reflux for about one hour.

\section{Oligomer}

A solution of $4,4^{\prime}$-dihydroxybiphenyl $(0.04$ mol) dissolved in $300 \mathrm{ml}$ of dry toluenepyridine $(4: 1)$ was added to sebacoyl chloride $(0.1 \mathrm{~mol})$ and subjected to reflux for an hour. Then $p$-phenylphenol $(0.2 \mathrm{~mol})$ was added, followed by additional reflux for an hour. After the reaction, the hot liquid was poured into $500 \mathrm{ml}$ of methanol to produce oligomers in the form of a white precipitate.

\section{Polymer}

A solution of $4,4^{\prime}$-dihydroxybiphenyl (0.1 $\mathrm{mol})$ dissolved in $300 \mathrm{ml}$ of dry toluenepyridine (4:1) was added to sebacoyl chloride $(0.1 \mathrm{~mol})$ and allowed to undergo reaction as in the case of oligomer production. Viscosity measurement was not performed for the polymer. In view of the data of the transition temperatures given by Krigbaum et al., ${ }^{4}$ the polymer was considered to have a proper degree of polymerization.

\section{Separation and Identification of Oligomers}

The reaction product as obtained was dissolved in hot xylene (insoluble residue was removed by filtration before cooling) and poured into a silica gel column (Merk Silica Gel 60). Xylene, toluene, and benzene were used as eluents to perform separation at $70^{\circ} \mathrm{C}$. Elemental analysis and NMR observation were carried out for identification of the materials obtained. Purity verification was per- 
formed with a GPC apparatus equipped with a UV detector. Two Showa Denko Co. HF 2003 columns $(20$ dia $\times 500 \mathrm{~mm})$ with a THF eluent were used with a column temperature and flow rate of $54^{\circ} \mathrm{C}$ and $3 \mathrm{ml} \mathrm{min}^{-1}$, respectively.

\section{Measurements}

Thermal analysis was carried out with 1.0 $1.2 \mathrm{mg}$ solution-crystallized samples on a Seiko SSC560 differential thermal analyzer at a heating rate of $5^{\circ} \mathrm{Cmin}^{-1}$. The heat of fusion was determined from the area defined by the endothermic curve, with indium as reference. The nature of the mesophase was studied using a Olimpus $\mathrm{BH}-2$ polarizing microscope equipped with a Mettler FP80/82 heating stage.

\section{RESULTS AND DISCUSSION}

Figure 1 illustrates the DSC heating curves of the three oligomer fractions, separated through sequential extraction with a Soxhlet extractor, and the polymer. During heating, the toluene extract (oligomer-a) showed no liquid crystalline phase, while THF extract (oligomer-b), and THF extraction residue (oligomer-c) showed a nematic mesophase in the respective temperature ranges: $178-191$, $178-212^{\circ} \mathrm{C}$, by optical microscopy. As compared with the oligomer-b, the oligomer-c

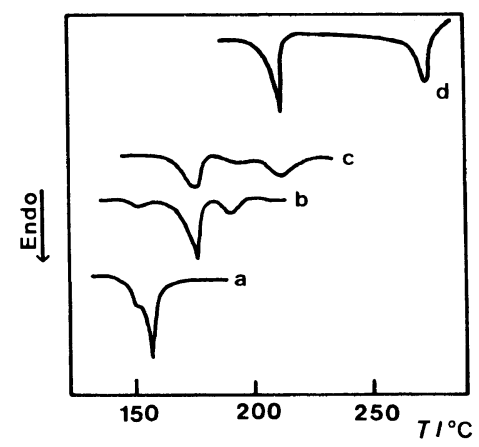

Figure 1. DSC heating curves of three oligomer fractions (B8) ${ }_{m}$ B and a polymer: (a) toluene extract; (b) THF extract; (c) THF extraction residue; (d) polymer. showed a broader liquid crystalline region and had a larger nematic-isotropic transition heat. The monomer B8B showed no liquid crystalline phase. The polymer showed a non-nematic viscous liquid crystalline phase, indicating that the phase is smectic in the range from $211^{\circ} \mathrm{C}$ to $276^{\circ} \mathrm{C}$, in accordance with the data reported by Krigbaum et $a l^{4}$ Thus the oligomers and polymer seem to have the following feature: a liquid crystalline phase develops at a certain polymerization degree, followed by change from monotropic nematic to enantiotropic nematic and then to smectic as the polymerization degree further increases. It is inferred that the disagreement between the experimental results by Krigbaum et $a .^{4}$ and by van Ruyen et al. ${ }^{5}$ may be attributable to the difference in the polymerization degree of the samples used.

The above results are with polydisperse samples. Oligomer-b, for example, consists of many components as indicated by the GPC measurement in Figure 2a. Peak 1 is ascribed to the B8B monomer. The logarithm, $\ln t$, of the retention time, $t$, of each sample was found proportional to the number $m$. This number corresponds to each mer, as will be described later. Thus, oligomer-b consists mainly of tri-

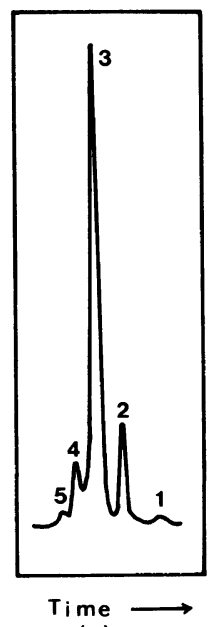

(a)

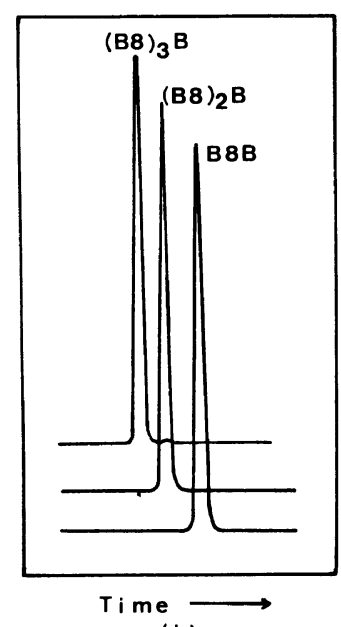

(b)
Figure 2. GPC curves of oligomers: (a) THF extract; (b) B8B, (B8) ${ }_{2} \mathrm{~B}$ and $(\mathrm{B} 8)_{3} \mathrm{~B}$. 
mers together with smaller amounts of monomers, dimers, tetramers, etc. A detailed investigation of each component of the oligomer material was required to reveal at which mer the formation of a liquid crystalline phase begins. Fortunately, it was possible to separate the material into three components (monomer to trimer) by making use of slight differences in the adsorptivity of components to silica gel. Fractions were identified as monomer B8B, dimer $(B 8)_{2} B$, and trimer $(B 8)_{3} B$, respectively, by elemental analysis. NMR measurements also supported the results. Figure $2 b$ shows GPC elution curves, which demonstrate that separation is achieved well up to the trimer. Being insoluble, the other oligomers including the tetramer were not able to be separated. B8B Anal. Calcd for $\mathrm{C}_{34} \mathrm{H}_{34} \mathrm{O}_{4}:$ C, $80.60 \%$;

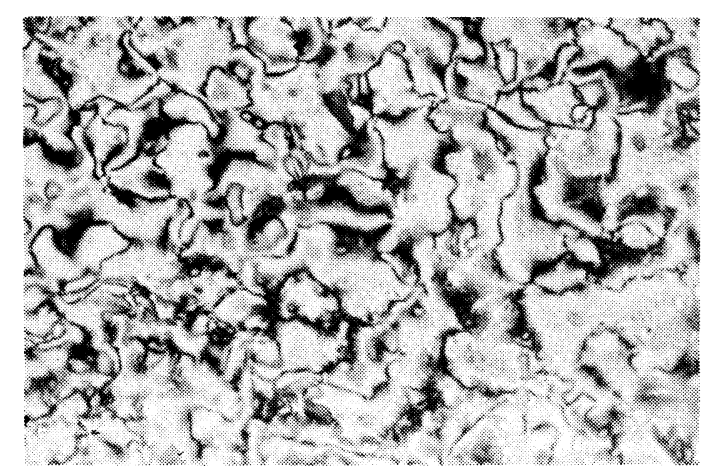

Figure 3. An optical micrograph of (B8) $)_{3} \mathrm{~B}$ at $186^{\circ} \mathrm{C}$. The sample was cooled rapidly from $200^{\circ} \mathrm{C}$ to $186^{\circ} \mathrm{C}$ $(150 \times)$.
$\mathrm{H}, 6.76 \%$. Found: $\mathrm{C}, 80.32 \% ; \mathrm{H}$, $6.76 \%$.

(B8) ${ }_{2} \mathrm{~B}$ Anal. Calcd for $\mathrm{C}_{56} \mathrm{H}_{58} \mathrm{O}_{8}: \mathrm{C}, 78.29 \%$; $\mathrm{H}, 6.80 \%$. Found: C, $78.19 \%$; $\mathrm{H}$, $6.79 \%$.

(B8) ${ }_{3} \mathrm{~B}$ Anal. Calcd for $\mathrm{C}_{78} \mathrm{H}_{82} \mathrm{O}_{12}:$ C, $77.33 \%$; H, $6.82 \%$. Found: C, $77.74 \%$ : $\mathrm{H}, 6.87 \%$.

No liquid crystalline phase was found in B8B and (B8) ${ }_{2}$ B by optical microscopy. During heating, $(\mathrm{B} 8)_{3} \mathrm{~B}$ showed no liquid crystalline phase either, but during cooling Schlieren and marble textures characteristic of the nematic phase were detected in the range from

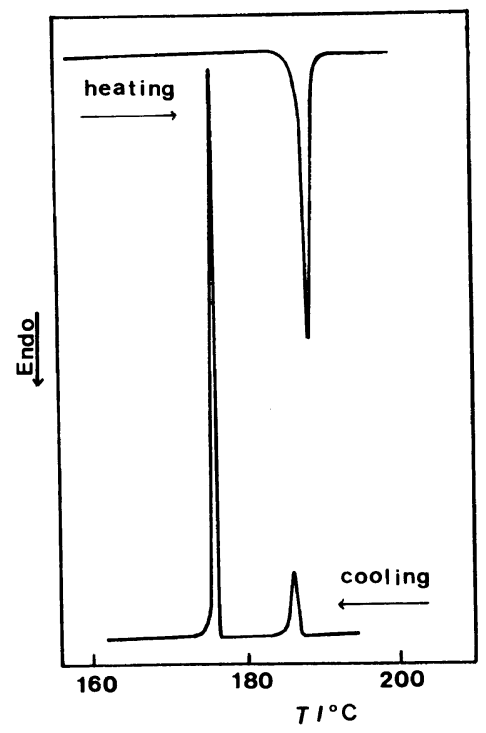

Figure 4. DSC heating and cooling curves of $(\mathrm{B} 8)_{3} \mathrm{~B}$.

Table I. Thermodynamic properties of (B8) ${ }_{m}$ B and BnB

\begin{tabular}{|c|c|c|c|c|c|c|c|c|c|}
\hline & $T_{\mathrm{KI}}$ & $T_{\mathrm{IN}}{ }^{\mathrm{a}}$ & $T_{\mathrm{NK}}^{\mathrm{a}}$ & $\Delta H_{\mathrm{Kl}}$ & $\Delta S_{\mathrm{KI}}$ & $\Delta H_{\mathrm{IN}}^{\mathrm{a}}$ & $\Delta S_{\mathrm{IN}}^{\mathrm{a}}$ & $\Delta s_{\mathrm{KI}}(1)$ & $\Delta s_{\mathrm{KI}}(2)$ \\
\hline & ${ }^{\circ} \mathrm{C}$ & ${ }^{\circ} \mathrm{C}$ & ${ }^{\circ} \mathrm{C}$ & $\mathrm{kJ} \mathrm{mol}^{-1}$ & $\mathrm{~J}\left(\mathrm{~mol} \mathrm{~K}^{-1}\right)$ & $\mathrm{kJ} \mathrm{mol}^{-1}$ & $\mathrm{~J}\left(\mathrm{~mol} \mathrm{~K}^{-1}\right)$ & $\mathbf{J}\left(\mathrm{mru}^{\mathrm{b}} \mathrm{K}^{-1}\right)$ & $\mathrm{J}\left(\mathrm{mru}^{\mathrm{b}} \mathrm{K}^{-1}\right)$ \\
\hline B8B & 143 & - & - & 65.5 & 157 & - & - & 79 & - \\
\hline$(\mathrm{B} 8)_{2} \mathrm{~B}$ & 172 & - & - & 86.1 & 193 & - & - & 64 & 36 \\
\hline$(\mathrm{B} 8)_{3} \mathrm{~B}$ & 189 & 187 & 176 & 125 & 271 & 23.9 & 52.0 & 68 & 57 \\
\hline B4B & 164 & - & - & 40.0 & 92 & - & - & - & - \\
\hline B6B & 147 & - & - & 51.8 & 123 & - & - & - & - \\
\hline B10B & 139 & 一 & - & 78.1 & 190 & - & - & - & - \\
\hline
\end{tabular}

a Values obtained from the cooling curve on DSC.

b Mole(s) of repeating unit. 
$187^{\circ} \mathrm{C}$ to $179^{\circ} \mathrm{C}$. Figure 3 shows an optical micrograph of $(\mathrm{B} 8)_{3} \mathrm{~B}$ at $186^{\circ} \mathrm{C}$. In the DSC measurement, $(\mathrm{B} 8)_{3} \mathrm{~B}$ gave only one sharp endothermic peak during heating, but two exothermic peaks at $187^{\circ} \mathrm{C}$ and $176^{\circ} \mathrm{C}$ during cooling, corresponding to the optical observation. The DSC curve of $(\mathrm{B} 8)_{3} \mathrm{~B}$ is illustrated in Figure 4.

Table I shows thermal data obtained by DSC measurement, with $\mathrm{K}, \mathrm{N}$, and I denoting crystal, nematic liquid crystal, and isotropic liquid, respectively. For thermodynamic investigation of polymeric liquid crystals, it is important to determine the K-I transition entropy per repeating unit, $\Delta s_{\mathrm{KI}}$, the most essential quantity. However, accurate determination of $\Delta s_{\mathrm{KI}}$ is generally difficult for polymers. Grebowicz et al. ${ }^{6}$ have attributed this difficulty not only to their low crystallinity but also to the large, rigid mesogen group forcing the flexible spacers in the crystal to become poorly oriented. Compared with this, the model compound has a high crystallinity and good orientation of the flexible spacers, permitting accurate determination of its $\Delta s_{\mathrm{KI}}$ if the effect of the end group is evaluated correctly. Various approaches have been proposed for evaluation of the quantity per repeating unit of model compounds. We define $(\mathrm{B} 8)_{m} \mathrm{~B}$ as $\mathrm{E}-$ $\mathbf{M}_{m-1}-\mathrm{E}$, where $\mathbf{M}$ and $\mathrm{E}$ represent the repeating unit and the terminal mesogenic group, as shown below.
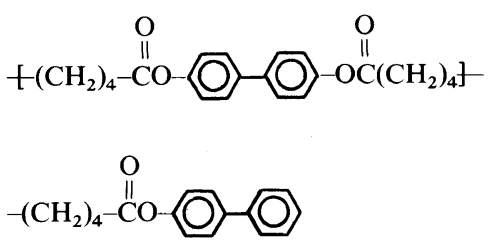

That is to say, $\mathrm{B} 8 \mathrm{~B},(\mathrm{~B} 8)_{2} \mathrm{~B}$, and $(\mathrm{B} 8)_{3} \mathrm{~B}$ may be represented by $\mathrm{E}-\mathrm{E}, \mathrm{E}-\mathrm{M}-\mathrm{E}$, and $\mathrm{E}-\mathrm{M}-\mathrm{M}-\mathrm{E}$, respectively. Two different approaches were used to estimate $\Delta s_{\mathrm{KI}}$ from the $\mathrm{K}-\mathrm{I}$ transition entropies of $(\mathrm{B} 8)_{m} \mathrm{~B}, \Delta S_{\mathrm{KI}}$. The results are given in Table $\mathrm{I}$. The $\Delta s_{\mathrm{KI}}(1)$ were calculated simply by dividing $\Delta S_{\mathrm{KI}}$ by $m+1$ on the assump- tion that $\mathrm{M}$ and $\mathrm{E}$ are equal in contribution to $\Delta S_{\mathrm{KI}}$. On the other hand, $\Delta s_{\mathrm{KI}}(2)$ were calculated as follows: For $(\mathrm{B} 8)_{2} \mathrm{~B}, \Delta s_{\mathrm{KI}}(2)=$ $\Delta S_{\mathrm{KI}}(\mathrm{E}-\mathrm{M}-\mathrm{E})-\Delta S_{\mathrm{KI}}(\mathrm{E}-\mathrm{E})=36\left(\mathrm{~J}\left(\mathrm{mru} \mathrm{K}^{-1}\right)\right)$. For $\quad(\mathrm{B} 8)_{3} \mathrm{~B}, \quad \Delta s_{\mathrm{KI}}(2)=\left[\Delta S_{\mathrm{KI}}(\mathrm{E}-\mathrm{M}-\mathrm{M}-\mathrm{E})-\right.$ $\left.\Delta S_{\mathrm{KI}}(\mathrm{E}-\mathrm{E})\right] / 2=57 \quad\left(\mathrm{~J}\left(\mathrm{mru} \mathrm{K}^{-1}\right)\right)$. Separation of the tetramer would have permitted a more accurate determination of the $\Delta s_{\mathrm{KI}}$ value. As far as being estimated from the data on the monomer to trimer, $\Delta s_{\mathrm{KI}}$ is considered to be in the range from 60 to $70\left(\mathrm{~J}\left(\mathrm{mru} \mathrm{K}^{-1}\right)\right)$. A similar value is also expected for the polymer consisting of the same repeating unit. Krigbaum et al. reported that $\Delta s_{\mathrm{KI}}=61.0$ $\left(\mathrm{J}\left(\mathrm{mru} \mathrm{K}^{-1}\right)\right){ }^{4}$ and Blumstein et al. that $\Delta s_{\mathrm{KI}}=$ $35.0\left(\mathrm{~J}\left(\mathrm{mru} \mathrm{K}^{-1}\right)\right){ }^{7}$ for polymers composed of the same repeating unit. The former value is close to our value and seems appropriate. The latter value seems small. The disagreement may be attributable to difference in crystallinity.

For low molecular weight liquid crystals, the ratio of $\Delta S_{\mathrm{NI}} / \Delta S_{\mathrm{KI}}$ is generally used as a measure to represent the degree of order in the nematic phase relative to that of the crystalline phase. This ratio has been reported to be in the range of $0.03-0.05$ for RF-type (rigidflexible sequence) and FRF-type (flexible-rigidflexible) liquid crystals, about 0.1 for RFRtype (rigid-flexible-rigid) liquid crystals, ${ }^{8}$ and $0.1-0.3$ for polymers. ${ }^{9}$ The $\Delta S_{\mathrm{IN}} / \Delta S_{\mathrm{KI}}$ of (B8) ${ }_{3} \mathrm{~B}$, which forms a monotropic nematic phase, is 0.19 , which is in the same range as that of polymeric liquid crystals and larger by far than that of general nematic liquid crystals of low molecular weight compounds. As in the case of $\Delta s_{\mathrm{KI}}$, even the trimer shows a polymeric nature with respect to the degree of order in the nematic phase.

At present, there are no clear answers about how a liquid crystalline phase develops as the polymerization degree increases, and why the nematic phase formed has a high degree of order. In order to obtain a clue to the clarification of the liquid crystalline phase formation process, the effects of the mesogen group, end 
group, and flexible segments on the liquid crystal formation capability have been examined as follows. No liquid crystals have been reported for esters (RF-type) formed from a fatty acid and $p$-phenylphenol, ${ }^{10}$ and none of our BnB samples ( $n=4-10$, RFR-type) show a liquid crystalline phase (Table I), suggesting that $p$-phenylphenol, despite being a rigid group, may have none or only an extremely weak, liquid crystal formation capability. For 4,4'-dihydroxybiphenyl, the ester with acetic acid can form monotropic nematic phase, ${ }^{10}$ indicating that $4,4^{\prime}$-dihydroxybiphenyl is a mesogen with a weak liquid crystal formation capability. Since (B8) ${ }_{2}$ B does not form a liquid crystalline phase, long methylene segments seem to act to reduce the liquid crystal formation capability because of their dilution effect. (B8) ${ }_{3} B$ forms a monotropic nematic phase. A reduction in the dilution effect may be a factor in the development of the nematic phase. For instance, $(\mathrm{B} 8)_{2} \mathrm{~B}$ contains 16 methylenes per mesogen group while $(\mathrm{B} 8)_{3} \mathrm{~B}$ contains only 12 methylenes per mesogen group. Preliminary experiments revealed that $(\mathrm{B} 6)_{3} \mathrm{~B}$ formed an enantiotropic nematic phase, while $(\mathrm{B} 10)_{3} \mathrm{~B}$ did not form a liquid crystalline phase, indicating that the ratio of the number of mesogen groups to that of methylene groups

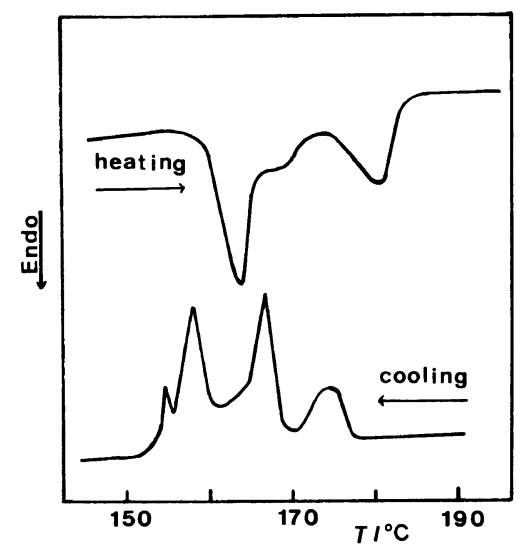

Figure 5. DSC heating and cooling curves of typical $(\mathrm{B} 8)_{2} \mathrm{~B}-(\mathrm{B} 8)_{3} \mathrm{~B}$ mixture (mol fraction of $(\mathrm{B} 8)_{3} \mathrm{~B}, x_{2}=$ $0.52)$. may have an important role in the development of the liquid crystalline phase.

Not only the polymerization degree but also the its distribution may have a large effect on the formation of a liquid crystal. Though composed mainly of $(\mathrm{B} 8)_{3} \mathrm{~B}$, which is monotropic, the oligomer-b showed an enantiotropic nematic phase over a wide range of $13^{\circ} \mathrm{C}$ (Figures 1 and $2 \mathrm{a}$ ), suggesting that a small amount of other large mers can have a large effect on the development of the liquid crystalline phase. We mixed the pure $(\mathrm{B} 8)_{2} \mathrm{~B}$ and
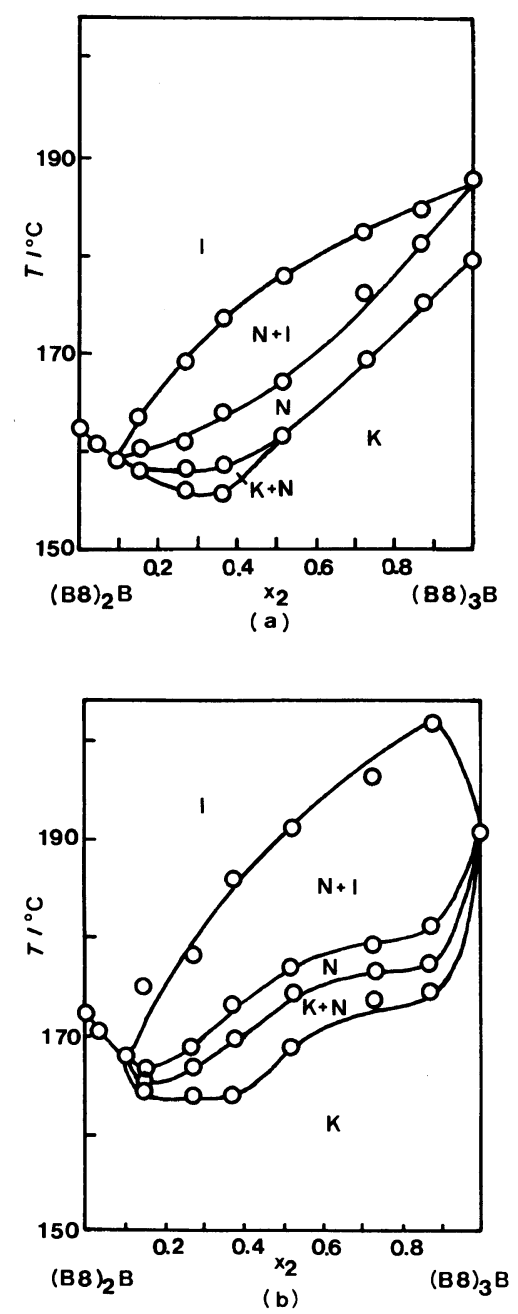

Figure 6. Phase diagrams for binary mixtures of (B8) ${ }_{2}$ B and (B8) ${ }_{3}$ B by microscopy: (a) on cooling; (b) on heating. 
$(\mathrm{B} 8)_{3} \mathrm{~B}$ in different mixing ratios and investigated the transition behavior. Figure 5 illustrates the DSC heating and cooling curves of a typical (B8) ${ }_{2} \mathrm{~B}-(\mathrm{B} 8)_{3} \mathrm{~B}$ mixture (mol fraction of $\left.(\mathrm{B} 8)_{3} \mathrm{~B}, x_{2}=0.52\right)$. The sample was cooled at a rate of $5^{\circ} \mathrm{C} \mathrm{min}^{-1}$ after being maintained at $200^{\circ} \mathrm{C}$. Four exothermic peaks appeared at $175^{\circ} \mathrm{C}, 167^{\circ} \mathrm{C}, 158^{\circ} \mathrm{C}$, and $154^{\circ} \mathrm{C}$. Corresponding to this thermal behavior, transitions from the I phase to a $\mathrm{N}+\mathrm{I}$ biphase at $178^{\circ} \mathrm{C}$, from the $\mathrm{N}+\mathrm{I}$ biphase to the $\mathrm{N}$ phase at $167^{\circ} \mathrm{C}$, and from the $\mathrm{N}$ phase to the $\mathrm{K}$ phase at $161^{\circ} \mathrm{C}$ were observed by optical microscopy. In the $\mathrm{N}+\mathrm{I}$ biphase between $167^{\circ} \mathrm{C}$ and $178^{\circ} \mathrm{C}$, the ratio between the $\mathrm{N}$ and $\mathrm{I}$ phases changed continuously with temperature, with the proportion of the $\mathrm{N}$ phase increasing with decreasing temperature. Heating again at a rate of $5^{\circ} \mathrm{C} \mathrm{min}^{-1}$ after crystallization gave two endothermic peaks at $164^{\circ} \mathrm{C}$ and $182^{\circ} \mathrm{C}$ and a shoulder at around $169^{\circ} \mathrm{C}$. For the same sample, transitions from the $\mathrm{K}$ phase to the $\mathrm{K}+\mathrm{N}$ biphase at $167^{\circ} \mathrm{C}$, from the $\mathrm{K}+\mathrm{N}$ biphase to the $\mathrm{N}$ phase at $174^{\circ} \mathrm{C}$, from the $\mathrm{N}$ phase to the $\mathrm{N}+\mathrm{I}$ biphase at $176^{\circ} \mathrm{C}$, and from the $\mathrm{N}+\mathrm{I}$ biphase to the I phase at $191{ }^{\circ} \mathrm{C}$ were observed by microscopy.

Figure 6 presents phase diagrams of a mixture of (B8) ${ }_{2} \mathrm{~B}$ and $(\mathrm{B} 8)_{3} \mathrm{~B}$ by microscopy on cooling (apparent), and on heating. All mixtures, during the cooling process, showed a $\mathrm{N}+\mathrm{I}$ biphase and a $\mathrm{N}$ phase, and mixtures of $x_{2}=0.1-0.4$ further showed a $\mathrm{K}+\mathrm{N}$ biphase, too, except for the mixture of $x_{2}=0.04$ which did not form a liquid crystalline phase. The region containing the $\mathrm{N}+\mathrm{I}$ biphase was the largest at an $x_{2}$ of about 0.5 . During the heating process, all mixtures showed the $\mathrm{K}+\mathrm{N}$ biphase, $\mathrm{N}$ phase, and $\mathrm{N}+\mathrm{I}$ biphase, except for the mixture of $x_{2}<0.1$ which did not form a liquid crystalline phase. This phase diagram is of great interest in that a small amounts of other smaller mers contained can have a large effect on the development of the liquid crystalline phase. The finding that a monotropic nematic trimer forms an enantiotropic nematic liquid crystal after being mixed with a dimer with no liquid crystal formation capability demonstrates that distribution of polymerization is also a key factor, in addition to its degree, in the development of a polymeric liquid crystalline phase.

\section{REFERENCES}

1. Ch. K. Ober, J-I Jin, and R. W. Lenz, "Advance in Polymer Science 59," M. Gordon and N. A. Plate, Ed., Springer-Verlag, Tokyo, 1984, p 103.

2. R. B. Blumstein, E. M. Stickles, M. M. Gauthier, A. Blumstein, and F. Volino, Macromolecules, 17, 177 (1984).

3. Q-F Zhou, X-Q Duan, and Y-L Liu, Macromolecules, 19, 247 (1986).

4. W. R. Krigbaum, J. Watanabe, and T. Ishikawa, Macromolecules, 16, 1271 (1983).

5. D van Luyen and L. Strzelecki, Eur. Polym. J., 16, 303 (1980).

6. J. Grebowicz and B. Wunderrich, J. Polym. Sci., Polym. Phys. Ed., 21, 141 (1983).

7. A. Blumstein, K. N. Sivaramakrishnan, R. B. Blumstein, and S. B. Clough, Polymer, 23, 47 (1982).

8. R. B. Blumstein, M. D. Poliks, E. M. Stickles, A. Blumstein, and F. Volino, Mol. Cryst. Liq. Cryst., 129, 375 (1985).

9. W. R. Krigbaum and F. Salaris, J. Polym. Sci., Polym. Phys. Ed., 16, 883 (1978).

10. D. Demus, H. Demus, and H. Zaschke, "Flussige Kristalle in Tabellen," Ve. Grundstoff Industrie, Leipzig, 1976. 